\title{
Aprendizagem do professor: uma leitura possível
}

\author{
Teacher's learning: reading the possible
}

\author{
Jamille Vilas Boas ${ }^{1}$ • Jonei Cerqueira Barbosa ${ }^{2}$
}

Resumo: Este é um trabalho teórico que tem como objetivo revisitar o conceito de aprendizagem do professor à luz dos estudos de Jean Lave e Etienne Wenger. Exploramos o conceito de aprendizagem como uma mudança nos padrões de participação do sujeito em uma determinada prática, além de discutir sobre a prática pedagógica escolar. Concluímos que a aprendizagem do professor pode ser entendida como uma mudança nos padrões de participação na prática pedagógica em que este exerce a tarefa do ensino - aprendizagem na docência - e mudanças nos padrões de participação em outras práticas que podem provocar a mudança na participação na prática pedagógica escolar - aprendizagem para a docência.

Palavras-chave: Formação continuada de professores. Aprendizagem. Prática pedagógica. Participação.

\begin{abstract}
This is a theoretical work that aims to re-visit the concept of teacher's learning based on Jean Lave's and Etienne Wenger's studies. We explored the concept of learning as a change in the subject's participation patterns in a particular practice, and discuss the school pedagogical practice. We conclude that the teacher's learning can be understood as a change in patterns of participation in pedagogical practice in holding the task of teaching - learning in teaching - and changing patterns of participation in other practices that may lead to change in participation in pedagogical practice school - learning to teaching.
\end{abstract}

Keywords: Teacher`s education. Learning. Teaching practice. Participation.

\footnotetext{
${ }^{1}$ Instituto Federal da Bahia (IFBA), Salvador, BA, Brasil. E-mail: <jamille@ifba.edu.br>.

${ }^{2}$ Universidade Federal da Bahia (UFBA), Salvador, BA, Brasil.
} 


\section{Introdução}

Este artigo é parte de uma pesquisa mais ampla, que possui como conceito central a aprendizagem do professor. Nesse sentido, observamos a necessidade de entender este conceito de forma consonante com as perspectivas de Jean Lave e Etienne Wenger (LAVE, 1991, 1996; LAVE; WENGER, 1991), já que este é o referencial teórico adotado na macro-pesquisa.

Segundo Graven (2004), há um crescente número de pesquisas em Educação que têm utilizado essas lentes teóricas, porém, nessa perspectiva, o maior número das pesquisas é sobre a aprendizagem ${ }^{3}$ do aluno (KRUMMHEUER, 2011). A aprendizagem docente é um assunto menos explorado. Segundo Davis e Krajcik (2005), é possível encontrar similaridades entre o aprendizado do professor e o aprendizado do aluno. Entretanto, a aprendizagem do professor tem diversas particularidades que precisam ser analisadas: envolve o conteúdo ensinado, os saberes pedagógicos sobre o conteúdo, as diretrizes curriculares, as relações sociais estabelecidas pelo professor, além do contexto em que o professor está inserido.

A aprendizagem do professor pode ocorrer em diferentes contextos, incluindo a sala de aula, a comunidade escolar, cursos de formação profissional e congressos (BORKO, 2004). Explorar esse conceito pode nos permitir entender como os professores aprendem nesses contextos, possibilitando implicações para a formação docente. Salientamos aqui a diferença entre a formação e a aprendizagem docente. A formação do professor inclui a formação inicial e continuada, considerando-se os modelos, teorias e investigação empírica sobre a formação, analisando-se a legislação e a regulamentação para promovê-la (PONTE, 1998). A aprendizagem pode ocorrer no processo de formação docente, porém não se reduz a essa, podendo ocorrer em diferentes contextos, como mencionamos anteriormente, mesmo naqueles que não foram delineados com tal propósito.

Este artigo, assim, é um trabalho teórico que tem como objetivo revisitar o conceito de aprendizagem do professor a luz dos trabalhos de Lave e Wenger (LAVE; WENGER, 1991; LAVE, 1991; LAVE, 1996). O uso do prefixo "re", em destaque, indica não somente uma repetição da ação de visitar o conceito já abordado pelos autores, mas também ressignificá-lo, na medida em que esta nova visita ajuda a ampliar o entendimento do mesmo. Chamamos atenção, entretanto, de que o entendimento sobre aprendizagem que será apresentado neste artigo é apenas uma das possíveis leituras, a partir dos trabalhos desses autores. Na próxima seção, será abordado como entendemos a aprendizagem na Perspectiva Situada. Em seguida, discutiremos também sobre a prática de professores e, por fim, faremos uma releitura sobre o conceito de aprendizagem deste profissional.

\section{A aprendizagem como participação}

A aprendizagem pode ser relacionada às formas de participação (DAVID; WATSON, 2008; KRUMMHEUER, 2011; LAVE, 1996; LAVE, WENGER, 1991), sobretudo quando

\footnotetext{
${ }^{3}$ As expressões aprendizagem e aprendizagem docente serão definidas em termos mais precisos no decorrer do artigo. Por ora, considere de maneira intuitiva. 
analisada em termos da participação do sujeito em práticas sociais relativamente circunscritas (SFARD, 2006). Assim, muda-se “o foco analítico do indivíduo enquanto alguém que aprende, para o aprender como participação no mundo social e do conceito de processo cognitivo para a visão de prática social” (LAVE; WENGER, 1991, p. 43, tradução nossa).

O conceito de prática é atribuído, nessa perspectiva, ao fazer num contexto histórico e social que dá estrutura e significado ao que se faz (WENGER,1998). Ao falar de uma prática, estamos nos referindo às ações que têm significado compartilhado por um certo grupo social, seja ele de professores, de alunos e de outros trabalhadores. Lave e Wenger (1991) analisam as ações de aprendizes de alfaiates, por exemplo. Estes têm contato com alfaiates mais experientes, inicialmente observando e depois seguindo os modos de agir para confeccionar peças de vestuário. Estas ações dos alfaiates e de seus aprendizes são parte de uma prática à medida que estão interagindo com ideias socialmente constituídas e compartilhadas.

Já o conceito de participação refere-se não a um mero envolvimento em uma atividade, mas é caracterizado quando há um reconhecimento mútuo deste envolvimento entre os membros da prática (WENGER, 1998). Retomando o exemplo dos alfaiates, é possível perceber um envolvimento dos aprendizes de alfaiates nas práticas dessa profissão. Além disso, há uma caracterização de reconhecimento mútuo por parte dos aprendizes e seus mestres naquela comunidade. As descrições apresentadas nos permitem afirmar que há um sentimento de pertencimento desses indivíduos àquelas práticas. Eles reconhecem-se naquelas práticas, o que permite afirmar que eles participam destas.

Em relação à prática escolar, há uma dificuldade de conceptualização dessa ideia, pois o envolvimento dos alunos nas práticas escolares, muitas vezes, não é voluntário. Dessa forma, o que representa se reconhecer como participante da prática escolar? Ao definir o conceito de participação, relacionando-o com o reconhecimento em uma determinada prática, Wenger (1998) estabelece uma restrição neste conceito. Há uma distinção entre situações voluntárias, como as relações de trabalho em que esta característica pode ser facilmente identificada, e as situações em que o indivíduo se envolve involuntariamente, como na escola (LERMAN, 1998).

A possibilidade de tomar um aluno como um participante da prática escolar pode ser subjetiva, pois a identificação do reconhecimento pode não ser explícita o suficiente para um observador, já que os alunos (na sua grande maioria) não pretendem se tornar matemáticos ou professores de Matemática (MATOS, 1999), por exemplo. Aqui, assumiremos reconhecer, mutuamente, como legitimar/responder às ações do outro ou do grupo social envolvido. Assim, em uma sala de aula, quando um professor convida os alunos a realizarem alguma tarefa, interage com eles, que seguem as orientações dadas pelo docente, respondem as perguntas, podemos afirmar que há um reconhecimento dos alunos em relação ao engajamento deles próprios e do professor, estão todos participando desta prática.

Neste sentido, ao afirmar que a aprendizagem está relacionada à participação, não quer dizer que qualquer participação na prática social pode ser vista como aprendizagem. Esta distinção é importante, senão, como relata Watson e Winbourne (2008, p. 6, tradução nossa), "há um perigo da construção de descrições de aprendizagens que incluem tudo o que fazemos, [...]. e podemos acabar sem distinções úteis do que é aprender".

Segundo Lave e Wenger (1991) a aprendizagem é um processo de tornar-se um participante pleno em determinada prática social. A participação é dita plena a depender dos tipos de interações que são legitimadas, como por exemplo, na sala de aula, em que aprender pode estar 
relacionado a responder como esperado pelo professor nas avaliações, ou pode estar relacionada a lidar com o comportamento do colega que está sentado atrás de você ou ser fluente em um determinado conteúdo (DAVID; WATSON, 2008). Assim, tornar-se um participante pleno refere-se a partilhar cada vez mais do que é relevante em determinada prática, e, ao mesmo tempo, construir novos significados a serem legitimados (LAVE; WENGER, 1991).

Além disso, ao descrever a aprendizagem em termos de "tornar-se" um determinado tipo de membro ou como uma "crescente participação” na prática social, Lave e Wenger (1991) relacionam a aprendizagem a um movimento, a uma mudança nas características das participações do sujeito. Então, podemos conceituar a aprendizagem como uma mudança na qualidade da participação do sujeito em uma prática social (BORKO, 2004; LAVE, 1996). Ao colocarmos a palavra qualidade em destaque, estamos sublinhando as caraterísticas da participação, seus padrões. Além disso, “a aprendizagem só parcialmente ou incidentalmente implica tornar-se capaz do envolvimento em atividades novas. As atividades, tarefas, funções e compreensões não existem isoladamente, são partes de sistemas de relações mais gerais nas quais têm significado" (MATOS, 1999, p. 3).

Winbourne (2008) traz o exemplo de aprendizagem da aluna Melissa, de 17 anos que frequentou aulas de Matemática em que a professora apoiava e incentivava o uso de calculadoras gráficas na sala de aula, bem como incentivava seus alunos a tornarem-se usuários independentes. Melissa adquiriu a calculadora e passou a utilizá-la com frequência nas aulas para responder diversos problemas com o auxílio da mesma, como incentivado pela professora. A estudante tornou-se uma participante cada vez mais especializada no uso da calculadora, não somente na sala de aula de Matemática. Ela também sugeriu à professora de Biologia a calculadora como ferramenta alternativa ao Excel para realização de análises desta disciplina.

Observemos que a aprendizagem de Melissa sobre o uso da calculadora permitiu a ela novas formas de participar de práticas sociais e implica não somente numa mudança pontual de sua participação. Segundo Lave e Wenger (1991, p. 53, tradução nossa) a aprendizagem implica "tornar-se uma pessoa diferente com respeito as possibilidades dos sistemas de relações", remetendo-nos a uma mudança ampla da participação do indivíduo em uma comunidade. Dessa forma, caso Melissa mudasse sua participação em um único momento, utilizando a calculadora como esperado pela professora, mas, posteriormente, não tenha participando desta maneira, isto não é entendido como aprendizagem, já que não alteraria a qualidade da participação de Melissa na prática pedagógica, ou seja, não a "tornaria uma pessoa diferente".

Assim, buscando dar conta desta necessidade, em que a aprendizagem é entendida como uma mudança na participação do sujeito, mas uma mudança ampla, que o torna um membro diferente na prática (LAVE, 1996; LAVE; WENGER, 1991), compreendemos a aprendizagem como uma mudança no padrão de participação do sujeito na prática social. Por padrão de participação, entendemos uma regularidade nas participações do sujeito. No caso da aluna Melissa, por exemplo, após a intervenção da professora de Matemática, ela passa a utilizar uma calculadora que adquiriu e indica em outras disciplinas o seu uso. Observemos que a participação de Melissa apresenta uma regularidade no uso da calculadora, o que entendemos como um padrão de participação. Dessa forma, podemos dizer que houve uma alteração naquilo que o sujeito é na prática social, ou seja, que houve aprendizagem (LAVE; WENGER, 1991). 


\section{A participação do professor e a prática pedagógica escolar}

O fazer do professor não se reduz à sala de aula, inclui outros contextos como a relação com a direção da escola, as atividades de formação, dentre outros. No entanto, é na aula que o professor relaciona-se com os alunos para exercer suas tarefas de ensino. Os professores projetam este fazer, incluindo metas e planos de tarefas. Ao implementá-los na sala de aula, precisam ajustá-los com base nas suas interações com os alunos (LEIKIN; ZAZKIS, 2010). Descrevemos, então, a prática social em que os professores estão envolvidos, circunscrevendo os fazeres referentes à tarefa de ensinar e aprender no contexto específico da educação formal e a esta prática social denominamos de prática pedagógica escolar.

Consideramos aqui a prática pedagógica escolar como parte de uma constelação de práticas que envolvem as atividades didáticas dentro da sala de aula, abrangendo os diferentes aspectos da escola e as relações desta com a sociedade, indo além do âmbito da escola. Sendo assim, o professor nesta prática pertence a uma comunidade social escolar e sua participação vai além das dimensões conceituais e procedimentais da disciplina que leciona, envolve também a organização escolar, a gestão da sala de aula, a relação com pais de alunos, dentre outras.

Uma comunidade social, seja ela escolar ou não, refere-se a um agrupamento de pessoas que compartilham linguagens e aprendem uns com os outros, por contato presencial ou virtual, com um objetivo ou necessidade de trocar experiências e técnicas (LAVE; WENGER, 1991). Na comunidade social escolar, entendemos que esta troca de experiência ou ainda a ideia de que os membros da comunidade aprendem uns com os outros não é equânime. Na relação professor/aluno, não há uma igualdade nesses papéis sociais, porém isto não descaracteriza esta comunidade, já que não há necessidade de que os diversos membros de uma comunidade social apresentem os mesmos aspectos referentes aos seus interesses e competências. A flexibilização dada ao conceito de comunidade social é um dos motivos que nos levou a optar por utilizá-lo ao invés do conceito de comunidade de prática, como apresentado por Wenger (1998).

Esta opção deve-se à definição de comunidade de prática, que envolve três características: interesse mútuo, empreendimento conjunto e repertório partilhado (WENGER, 1998). Ou seja, os membros de uma comunidade de prática desenvolvem não somente um repertório de experiências, histórias e artefatos que os qualificam para enfrentar certas situações que se tornam recorrentes, mas também apresentam um compromisso com o grupo e competências que diferem seus membros de outras pessoas. De maneira geral, um grupo formado apenas por alunos, ou por alunos e professores de uma determinada turma, ou apenas por professores de Matemática, pode caracterizar-se como comunidade de prática. Para tanto, é necessário que estes apresentem as três dimensões, como indicado por Wenger (1998), em maior ou menor grau.

Para utilizarmos o conceito de comunidade de prática, seria necessário observar cada uma dessas características e identificá-las em cada grupamento de pessoas, o que, para nós, não é um entendimento operacional para analisar comunidades de salas de aula (WATSON, WINBOURNE, 2008). Sustentamos que o conceito de comunidade de prática pode não ser central para o entendimento da aprendizagem (BARTON; TUSTING, 2005), podendo ser reelaborado para o conceito de comunidade social (LAVE; WENGER, 1991), o qual é um pouco mais flexível e ainda assim útil para o nosso objetivo.

Rocha e Fiorentini (2005) observaram e analisaram a prática de Luiza, uma professora de Matemática licenciada há um ano. Luiza relatou que, em seus primeiros dias de aula, a expe- 
riência foi permeada por satisfação, mas também por medo e angústia: diz que seus saberes de aluna pareciam não dar conta de sua nova realidade. É possível perceber, com o relato de Luiza, que a prática pedagógica em que ela estava inserida enquanto professora da educação básica se diferencia das demais práticas vivenciadas. Ela precisaria entender esta nova comunidade social que compartilha linguagens e objetivos próprios.

A prática pedagógica na educação formal é desenvolvida por professores e alunos. Os alunos têm contato com os professores, que, na maior parte das vezes, tem uma socialização maior com o repertório considerado legítimo a ser trabalhado em aula e um domínio sobre como será a dinâmica dessa aula. Nesta relação, o professor também aprende (LEIKIN; ZAZKIS, 2010), porém os papéis sociais dos professores e dos alunos estão dados como membros dessa prática, de forma que a relação com a aprendizagem na prática pedagógica também não é igual.

Mesmo tendo apenas um ano de formação, Luiza já lecionava anteriormente. No decorrer destes anos, ela relatou que passou a privilegiar a interpretação dos alunos e suas compreensões. Afirma que assim sentiu-se mais segura para atuar na sua profissão. Não fica muito claro no estudo de Rocha e Fiorentini (2005) porque Luiza passa a sentir-se mais segura, porque ela torna-se um participante distinto na prática pedagógica. Mas é possível que a troca de experiências com professores mais experientes, com a dinâmica da escola, com ações da direção, ouvindo sugestões de seus alunos e a participação em atividades de formação sejam alguns dos fatores que permitiram a Luiza compartilhar o que é relevante a esta comunidade social e desenvolver com mais segurança seu fazer docente.

A estas mudanças nos padrões de participação de Luiza na prática pedagógica escolar, que a torna um membro diferente nesta comunidade social (LAVE; WENGER, 1991), podemos denominar de aprendizagem docente à luz da Perspectiva Situada. Na seção que segue, discutiremos o conceito de aprendizagem docente a fim de delimitá-lo em termos da aprendizagem como participação. Além disso, faz-se notar que os exemplos abordados neste trabalho são sobre professores de matemática, pois é a área de formação dos autores.

\section{A aprendizagem docente}

A perspectiva proposta por Lave e Wenger (1991) para compreender a aprendizagem sugere o foco nas mudanças dos padrões de participação do sujeito em uma determinada prática, como descrito nas seções anteriores. Com relação a aprendizagem do professor, como sugerem Leikin e Zazkis (2010), mudanças nos padrões de participação docente na prática pedagógica escolar também estão vinculadas ao fazer docente na sala de aula.

Zazkis (2010), por exemplo, descreve um episódio de sua sala de aula, em que um estudante perguntou sobre o critério de divisibilidade de um número qualquer por 7 , o que não estava programado para ser falado naquela aula. Isso não só provocou nela a curiosidade de entender este critério, mas também o interesse em desenvolver testes similares para outros números que não são abordados nos livros didáticos. Além de desenvolver alguns desses critérios, é possível imaginar então que Zazkis, após a intervenção do aluno, pôde explorar com mais precisão este assunto na sala de aula.

Segundo a autora, o critério de divisibilidade de um número por 7 é parte da Matemática escolar e ela poderia ter estudado sobre isto de outras formas, mas foi a pergunta do 
aluno que desencadeou seu aprendizado, a sua mudança de participação na prática pedagógica escolar. Existem algumas participações dos alunos que "desafiam" o planejamento do professor, obrigam-no a repensar ou ampliar a sua prática, desenvolver um novo método ou redesenhar a sequência de aulas, em suma, os ajudar a aprender.

Podemos imaginar o professor, na prática pedagógica de que participa, fazendo tentativas e aprimoramentos. Neste caso, participações julgadas como bem sucedidas podem tornar-se parte desta prática (ZAZKIS, 2010). Assim, ao explicar sobre trigonometria, por exemplo, e ouvir uma mesma pergunta diversas vezes, o professor pode mudar seu modo de explicar e antecipar as perguntar dos alunos durante a sua fala, ocorrendo assim a aprendizagem docente. Podemos afirmar que esta aprendizagem é uma aprendizagem na própria docência, ou seja, estas mudanças nos padrões de participação do professor na prática pedagógica escolar são desencadeadas a partir de situações ocorridas no próprio exercício profissional.

Além disso, observamos exemplos na literatura, há situações em que há mudanças nos padrões de participação do sujeito que é professor para além da sala de aula, que podem repercutir na prática pedagógica escolar. Borko et al. (2000) apresentam um exemplo da professora Savant em um curso de formação que incorporou diversas atividades que vivenciou no curso de formação em sua sala de aula. Em uma tarefa sobre o cálculo da medida da área do círculo, por exemplo, a professora, além de tentar usá-la, utilizou outro recurso para potencializá-la - um software - que também conheceu no curso de formação. Além de mudanças bastante visíveis como as apresentadas, Savant também apresentou vocábulos novos, passou a encorajar os alunos a fazerem múltiplas representações e conjecturas, práticas vivenciadas no curso de formação. Ou seja, a aprendizagem de Savant no curso de formação repercutiu também na sua prática pedagógica. Dessa forma, consideramos esta também uma aprendizagem docente, mais especificamente, uma aprendizagem para a docência, já que pode repercutir na prática pedagógica.

De acordo com Wenger (1998), as nossas participações em diversas comunidades sociais, além da nossa não participação em outras comunidades, nos ajuda a moldar algumas características no sujeito. Nesse sentido, estas características são sociais, "formadas" a partir das nossas trajetórias em comunidades (ASKEW, 2008) que se manifestam como uma tendência para chegar a certas interpretações, para envolver-se em determinadas ações, fazer certas escolhas (WENGER, 1998). Dessa forma, ao participar do curso de formação ou outros ambientes em que ocorre a aprendizagem, o professor, assim como Savant, molda uma forma de participar que pode se manifestar em outras práticas por ele vivenciadas, como é o caso da prática escolar, possibilitando que a aprendizagem para a docência ocorra.

Neste sentindo, definimos a aprendizagem docente como a mudança nos padrões de participação do professor na prática pedagógica escolar, além de mudanças nos padrões de participações em outras práticas, que podem repercutir em mudanças de participação na prática pedagógica escolar. Assim como as mudanças nos padrões de participação de Luiza em sua sala de aula, decorridas de situações nessa prática, são entendidas como aprendizagem docente, as mudanças de participação em outras práticas, como cursos de formação e convívio com outros professores, as quais podem repercutir em mudanças de participação na prática pedagógica.

Não é qualquer aprendizado do sujeito que também é professor que caracterizamos como aprendizagem docente, mas somente aquele que pode repercutir na própria prática pedagógica. A aprendizagem docente pode ser de dois tipos: a aprendizagem na docência e a aprendizagem para a docência. Assim como Luiza, Zazkis e Savant, professores aprendem na 
sala de aula, ou fora dela. A aprendizagem docente é a mudança nos padrões de participação na prática pedagógica em que exerce a tarefa do ensino - aprendizagem na docência - e que pode provocar a mudança nesses padrões - aprendizagem para a docência - na prática pedagógica escolar.

\section{Conclusões}

Este trabalho teve como objetivo revisitar o conceito de aprendizagem do professor à luz dos estudos de Jean Lave e Etienne Wenger (LAVE, 1996; LAVE; WENGER, 1991). Delineamos, a partir de um entendimento da perspectiva situada, o conceito de aprendizagem como uma mudança nos padrões de participação do sujeito em uma determinada prática.

Para tratar da aprendizagem do professor, consideramos a prática pedagógica escolar, baseada nas definições de prática social de Wenger (1998), como aquela que circunscreve os fazeres referentes ao ensino e aprendizagem no contexto específico da educação formal. $\mathrm{O}$ modo de comunicar-se no ambiente escolar, a interação com os alunos, a elaboração de uma prova, momentos em que são partilhados, e significados entre estes sujeitos. Concluímos que a aprendizagem do professor é composta por duas aprendizagens: a aprendizagem na docência e a aprendizagem para a docência.

A aprendizagem na docência pode ser entendida como uma mudança nos padrões de participação do professor na prática pedagógica escolar desencadeada a partir de situações de ensino. Assim como, no exemplo da professora Zazki (ZAZKIS, 2010), aprendizagens na docência são frutos das relações estabelecidas nesta prática. A aprendizagem para a docência, por outro lado, são mudanças nos padrões de participação do professor em outras práticas que podem repercutir no seu fazer docente na prática pedagógica, como no exemplo da professora Savant (BORKO et al., 2000).

Essa composição nos permite concluir que nem todo aprendizado do sujeito, que também é professor, é caracterizado como aprendizagem docente, mas somente aquele que pode repercutir no seu fazer pedagógico. Além disso, podemos concluir, como Cedro (2008), que a aprendizagem docente somente pode ser entendida na relação com o ensino e a aprendizagem dos alunos, mas não se restringe à prática pedagógica escolar, já que a aprendizagem em outras práticas repercute na sala de aula, configurando a aprendizagem para a docência. A seguir, discutiremos as implicações desta concepção de aprendizagem docente para a formação do professor e para futuros estudos.

\section{Implicações para a formação docente e estudos futuros}

A partir do conceito de aprendizagem para a docência elaborado neste estudo, a aprendizagem do professor é caracterizada na possibilidade de repercutir no seu fazer pedagógico. Ao tratar da formação de professores, o interessante é que a aprendizagem nestes cursos possam repercutir e subsidiar a prática pedagógica escolar. No estudo de Borko et al. (2000), os autores procuram entender como alguns aspectos do curso de formação continuada repercutiam mais facilmente na sala de aula, em detrimento de outros, e sugerem que esta repercussão pode ser 
mais fluída quando há uma tentativa de tornar mais compatíveis os objetivos e visões do curso e a prática da sala de aula. Reforçam ainda, a ideia de que a universidade e a educação básica devem trabalhar em conjunto, como proposto nas diretrizes para formação de professores (BRASIL, 2002) e assim formar profissionais mais familiarizados com as práticas escolares de modo geral.

A prática pedagógica escolar e a prática nos cursos de formação são práticas de fronteira (WENGER, 1998), ou seja, há conexões entre essas práticas. Alguns documentos, conceitos e termos são usados em ambas as práticas, além de ter pessoas que introduzem elementos de uma prática na outra, o que Wenger (1998) denomina de broker. Ao brokeré necessária a percepção das conexões entre as práticas, para que possa transitar entre elas e inserir elementos que vivenciou em uma prática, na outra. O sujeito, ao participar do curso de formação e aprender sobre algo, participa de um modo diferente, molda características naquela comunidade social (WENGER, 1998). Da mesma forma, se este percebe que a prática no curso de formação apresenta similaridades com a prática escolar, é mais fácil manifestar essa forma de participar também na escola.

É possível identificar pelo menos três modos de conexão entre duas práticas: quando há uma terceira prática que faz fronteira com ambas, quando elas se sobrepõem e quando há conexões apenas periféricas (WENGER, 1998). Em relação à prática pedagógica escolar e à prática dos cursos de formação, uma possível conexão entre elas, que pode favorecer a ação dos brokers é de sobreposição. Nesta conexão, há muitos elementos e participantes engajados em ambas as práticas. Mesmo sendo práticas distintas, há uma sobreposição de componentes, o que pode tornar mais visível a relação das práticas.

Borko et al. (2008), por exemplo, estudam um modelo de formação continuada em Matemática, em que utilizam vídeos de professores em sala de aula para que os professores-alunos do curso possam analisar. É relatado que, após dois anos, eles falavam de forma mais focada e com profundidade analítica sobre a Matemática envolvida nos vídeos, além da prática pedagógica mostrada. Neste estudo, não há dados que nos mostre a repercussão desta aprendizagem na prática pedagógica de cada um dos professores-alunos do curso, porém podemos supor que este tipo de abordagem, quando aproxima estas práticas, torna mais fácil a ação do broker e permite que ocorram mudanças no padrão de participação do professor na prática pedagógica escolar.

Assim, uma proposta de formação docente que objetiva a aprendizagem para a docência, como entendido neste artigo, deve tentar aproximar as práticas do curso com a prática pedagógica do professor de Matemática de modo a sobrepô-las, já que o aluno do curso de formação precisa perceber como aquele modo de participar pode ser útil na prática pedagógica escolar. Uma sugestão para futuros estudos sobre o tema é analisar aspectos da aprendizagem na docência, ou ainda, buscar entender aspectos do desenvolvimento profissional que favorecem a aprendizagem para a docência.

\section{Referências}

ASKEW, M. Social identities as learners and teachers of mathematics. In: WATSON, A.; WINBOURNE, P. (Ed.). New direction for situated cognition in mathematics education. New York: Springer, 2008. p. 59-78.

BARTON, D.; TUSTING, K. Beyond communities of practices. Cambridge: Cambridge University Press, 2005. 
Vilas Boas, J.; Barbosa, J. C.

BORKO, H. Professional development and teacher learning: mapping the terrain.

Educational Researcher, Abingdon, v. 33, n. 8, p. 3-15, 2004.

BORKO, H. et al. Teacher education does matter: a situative view of learning to teach secondary mathematics. Educational Psychologist, Philadelphia, v. 35, n. 3, p. 193-206, 2000 .

. Video as a tool for fostering productive discussions in mathematics professional development. Teaching and Teacher Education, Kidlington, v. 24, n. 2, p. 417-436, 2008.

BRASIL. Conselho Nacional de Educação. Parecer CNE/CP 9/2001. Diretrizes para a formação de professores da educação básica, em nível superior, curso de licenciatura, de graduação plena. Diário Oficial da União, Brasília, 18 abr. 2002. Seção 1, p. 31. Disponível em: <http://portal.mec.gov.br/cne/arquivos/pdf/009.pdf>. Acesso em: 23 set. 2016.

CEDRO, W. L. O motivo e a atividade de aprendizagem do professor de matemática: uma perspectiva histórico-cultural. 2008. 242 f. Tese (Doutorado em Educação) Universidade de São Paulo, São Paulo, 2008.

DAVID, M. M.; WATSON, N. Participating in what?: using situated cognition theory to illuminate differences in classroom practices. In: WATSON, A.; WINBOURNE, P. (Ed). New directions for situated cognition in mathematics education. New York: Springer, 2008. p. 31-58.

DAVIS, E. A.; KRAJCIK, J. S. Designing educative curriculum materials to promote teacher learning. Educational Researcher, Abingdon, v. 34, n. 3, p.3-14, 2005.

GRAVEN, M. Investigating mathematics teacher learning within an in-service community of practice: the centrality of confidence. Educational Studies in Mathematics, Dordrecht, v. 57, n. 2, p. 177-211, 2004.

KRUMMHEUER, G. Representation of the notion "learning-as-participation" in everyday situations of mathematics classes. ZDM: the international journal on mathematics education, Heidelberg, v. 43, n. 1, p. 81-90, 2011.

LAVE, J. Situating learning in communities of practice. In: RESNICK L. B.; LEVINE, J. M.; TEASLEY, S. (Ed.). Perspectives on socially shared cognition. Washington: American Psychological Association, 1991. p. 63-82.

. Teaching, as learning, in practice. Mind, Culture, and Activity, Philadelphia, v. 3, n. 3, p. 149-161, 1996.

LAVE, J.; WENGER, E. Situated learning: legitimate peripheral participation. New York: Cambridge University Press, 1991.

LEIKIN, R.; ZAZKIS, R. Teachers' opportunities to learn mathematics through teaching. In: . (Ed.). Learning through teaching mathematics. London: Springer, 2010. p. 3-22.

LERMAN, S. Learning as social practice: an appreciative critique. In: WATSON, A. (Ed.). Situated cognition and the learning of mathematics. Oxford: University of Oxford, 1998. p. 33-42. 
MATOS, J. F. Aprendizagem e prática social: contributos para a construção de ferramentas de análise da aprendizagem matemática escolar. In: PONTE, J. P.; SERRAZINA, L. (Org.). Educação matemática em Portugal, Espanha e Itália: actas da Escola de Verão. Lisboa: SEM-SPCE, 1999. p. 65-92.

PONTE, J. P. Da formação ao desenvolvimento profissional. In: ENCONTRO

NACIONAL DE PROFESSORES DE MATEMÁTICA ProfMat, 1998, Guimarães. Actas... Lisboa: APM, 1988. p. 27-44.

ROCHA, L. P.; FIORENTINI, D. O desafio de ser e constituir-se professor de matemática durante os primeiros anos de docência. In: REUNIÃO ANUAL DA ANPED, 28., 2005, Caxambu. Anais... Disponível em: <http://www.ufrrj.br/emanped/paginas/conteudo_ producoes/docs_28/desafio.pdf>. Acesso em: 23 set. 2016.

SFARD, A. Participationist discourse on mathematics learning. In: MAASZ, J.; SCHLOEGLMANN, W. (Ed.). New mathematics education research and practice. Rotterdam: Sense, 2006. p. 153-170.

ZAZKIS, R. What have I learned: mathematical insights and pedagogical implications. In: LEIKIN, R.; ZAZKIS, R. (Ed.). Learning through teaching mathematics. London: Springer, 2010. p. 91-110.

WATSON, A.; WINBOURNE, P. Introduction. In: (Org.). New directions for situated cognition in mathematics education. New York: Springer, 2008. p. 1-12. WENGER, E. Comunities of pratices learning, meaning, and identity. Cambridge: Cambridge University Press, 1998.

WINBOURNE, P. Looking for learning in practice: how can this inform teaching. In: WATSON, A.; WINBOURNE, P. (Org.). New directions for situated cognition in mathematics education. New York: Springer, 2008. p. 79-102. 